\section{Is MRI a predictive biomarker for clinical response to biologics in rheumatoid arthritis?}

We thank Sewerin et $a l^{1}$ for the data they have provided on the predictive role of MRI for clinical response in rheumatoid arthritis (RA). This study follows on from our previous study demonstrating the predictive value of MRI for radiographic damage progression. $^{2}$ This study by Sewerin builds on the evidence for MRI as an imaging biomarker by demonstrating a prediction of clinical response. The investigators used the German REMISSION-PLUS ${ }^{3}$ cohort and studied 29 patients who were being escalated to biologic therapy due to inadequate disease control. Clinical European League Against Rheumatism response to the biologic was more likely in those with higher RA MRI scores prior to the escalation of therapy. While these study results need to be replicated in a larger cohort, this study provides initial evidence that MRI measures can help predict who is most likely to benefit from more aggressive interventions.

The concept that MRI more accurately identifies clinically relevant synovitis than clinical assessment is well established. ${ }^{4}$ One hypothesis for why MRI might be a useful predictive biomarker for therapeutic response is that some patients with apparently active RA have elevated disease activity measures due to comorbid conditions, rather than active joint inflammation. For example, a recent study showed that obese patients are less likely to reach clinical remission. ${ }^{5}$ Those with elevated disease activity measures without objective evidence of inflammatory disease would be very unlikely to improve with more aggressive treatment of the RA. In contrast, those with greater MRI-detected activity might be expected to have a greater proportion of their clinical disease activity explained by active RA.

Limitations of this study are the small sample size and lack of a more detailed characterisation of the study population. However, this study begins to answer an important question in RA, namely-can MRI help rheumatologists make more accurate decisions about escalation of therapy? Given that escalation to biologic therapy involves increased risk of side effects and cost, biomarkers that define both cases at greatest risk of joint destruction and those most likely to benefit clinically are of major interest. MRI, despite being expensive, is likely to be costeffective in circumstances when its use prevents unnecessary or inappropriate use of much more expensive and long-term therapies.

\section{Joshua F Baker, ${ }^{1,2,3}$ Mikkel Østergaard, ${ }^{4,5}$ Philip G Conaghan ${ }^{6}$}

${ }^{1}$ Philadelphia Veterans Affairs Medical Center, Philadelphia, Pennsylvania, USA

${ }^{2}$ University of Pennsylvania, School of Medicine, Philadelphia, Pennsylvania, USA

${ }^{3}$ Center for Clinical Epidemiology and Biostatistics, University of Pennsylvania, Philadelphia, Pennsylvania, USA

${ }^{4}$ Copenhagen Center for Arthritis Research, Center for Rheumatology and Spine Diseases, Rigshospitalet, Glostrup, Denmark

${ }^{5}$ Department of Clinical Medicine, Faculty of Health and Medical Sciences, University of Copenhagen, Copenhagen Denmark

${ }^{6}$ NIHR Leeds Musculoskeletal Biomedical Research Unit, Leeds Institute of Rheumatic and Musculoskeletal Medicine, University of Leeds, Leeds, UK

Correspondence to Dr Joshua F Baker, Philadelphia Veterans Affairs Medical Center, Philadelphia, PA 19104, USA; bakerjo@uphs.upenn.edu

Competing interests None declared.

Provenance and peer review Commissioned; internally peer reviewed.

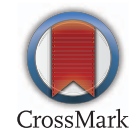

To cite Baker JF, Østergaard M, Conaghan PG. Ann Rheum Dis 2017;76:e45.

Received 7 February 2017

Revised 21 February 2017

Accepted 22 February 2017

Published Online First 10 March 2017

\section{Linked}

http://dx.doi.org/10.1136/annrheumdis-2017-211257

Ann Rheum Dis 2017;76:e45. doi:10.1136/annrheumdis-2017-211265

\section{REFERENCES}

1 Sewerin P, Vordenbaeumen S, Brinks R, et al. Prospective MRI-score to predict negative EULAR-response in patients with rheumatoid arthritis (RA) before therapy-escalation to a biological therapy. Ann Rheum Dis 2017;76:e44.

2 Baker JF, Ostergaard M, Emery $\mathrm{P}$, et al. Early MRI measures independently predict 1-year and 2-year radiographic progression in rheumatoid arthritis: secondary analysis from a large clinical trial. Ann Rheum Dis 2014;73:1968-74.

3 Ostendorf B, Scherer A, Kellner $H$, et al. [Project REMISSION(PLUS): clinical and radiological remission : new treatment goals in the management of rheumatoid arthritis]. Z Rheumatol 2008;67:707-10, 12-15.

4 Brown AK, Conaghan PG, Karim Z, et al. An explanation for the apparent dissociation between clinical remission and continued structural deterioration in rheumatoid arthritis. Arthritis Rheum 2008;58:2958-67.

5 Liu Y, Hazlewood GS, Kaplan GG, et al. Impact of obesity on remission and disease activity in rheumatoid arthritis: a systematic review and meta-analysis. Arthritis Care Res (Hoboken) 2017;69:157-65. 